\title{
Unusual Presentation of Silent Uterine Rupture: A Case Report
}

\author{
Manju Verma ${ }^{1, *}$ \\ ${ }^{1}$ Department of Obstetrics and Gynecology, King George's Medical University, Lucknow, India \\ “Corresponding author: Manju Verma, Department of Obstetrics and Gynecology,King George’s Medical University,Lucknow, India. E-mail: gaganmlv@gmail.com
}

Received 2015 September 19; Revised 2016 January 03; Accepted 2016 December 06.

\begin{abstract}
Uterine rupture is a major obstetric hazard. It may lead to significant maternal morbidity and mortality, which depends proportionally upon delay in diagnosis, transport facilities and availability of blood. Rupture uterus may be seen in both scarred and unscarred uterus but more commonly in scarred uterus. Usually post rupture patient goes into shock but here we present here a case of 35 years old multigravida woman who had silent rupture of scarred uterus. Incidence, causes and treatment part of uterine rupture is discussed here.
\end{abstract}

Keywords: Uterine Rupture

\section{Introduction}

Uterine rupture is an important complication in obstetrics. $5 \%-10 \%$ of maternal mortality is because of uterine rupture in developing countries (1). $80 \%-90 \%$ of fetuses in these cases could not be survived (2). Inadequate antenatal care is a root cause for high incidence of rupture uterus in developing countries. Incidence of uterine rupture is 1:200 to $1: 3000$ deliveries $(1,3,4)$ according to level of antenatal care. Rupture of entire uterine wall and direct connection between peritoneal space and uterine cavity is defined as complete rupture.

Rupture may occur both in scarred and nonscarred uterus. The American college of obstetricians and gynaecologists reported a 1 to $7 \%$ incidence of scar rupture in women with previous lower segment caesarean section(5). Cause for rupture in unscarred uterus may be abdominal trauma or hypertonic uterine contractions. Instrumental deliveries, internal podalic version, assisted breech delivery may be a cause for traumatic uterine rupture. Grand multipara and congenital malformed uterus (unicornuate and bicornuate uterus) may have spontaneous rupture.

\section{Case Presentation}

A 35-year-old unregistered woman G6P5003 (with three living issues) came to our hospital with off and on leaking and bleeding per vagina for 20 days following amenorrhea of 8 months with previous LSCS.

Patient was afebrile and pale. Her pulse was $94 \mathrm{bpm}$, regular, B.P. was $110 / 70 \mathrm{mmHg}$, RR was 20 beats / minute, chest was clear and cardiovascular system was normal. Previous vertical midline scar was healed by secondary intention. On per abdominal examination abdomen was rigid and fundal height was just below umbilicus. A vague tender mass was felt in right paracolic gutter. On per vaginal examination cervical os was open, a rent felt on anterior wall of uterus, uterus was 20 weeks size, firm in consistency and tender. On removing finger, a bunch of hair came out through cervical os.

Her hemoglobin was $9.5 \mathrm{gm} / \mathrm{dL}$, blood group was B positive, serum urea, serum creatinine and LFT were within normal limits. Laparotomy was done which showed thick pus in abdominal cavity with dense adhesions present between uterus and anterior abdominal wall and bladder. Vertical midline rupture was present on anterior wall of uterus and uterus was empty.

Baby was found in piecemeal in right paracolic gutter which was felt as vague mass on per abdominal examination. Subtotal hysterectomy was done followed by saline wash and after maintaining proper hemostasis, drain was put and abdomen was closed in layers. Postoperatively two units blood were transfused. Postoperative period was uneventful and patient was discharged on 10th day.

\section{Discussion}

Our case had a silent rupture of a previous scar following which the fetus was found in piece meals in right paracolic gutter. Whole of the abdominal cavity was full of pus. Finding of fetus in piecemeal in peritoneal cavity suggested chronic rupture uterus. Although there are case reports of silent uterine rupture in literature but to our best of knowledge, silent uterine rupture with chronic presentation (history of 20 days of off and on leaking and bleeding per vagina and finding of fetus in piecemeal in paracolic gutter) is unusual. 
Rupture uterus is one of the most dreaded complications in obstetrical practice $(5,6)$ and may lead to maternal death if not diagnosed and treated in time. The cases of ruptured uterus are mostly emergency admissions. Morbidity and mortality are proportional to delay in diagnosis, adequate transport facilities and availability of blood. Rupture uterus is more commonly seen in scarred uterus as compared to unscarred uterus $(7,8)$. It is more common in developing countries in comparison to developed countries whether it be scarred or unscarred uterus (2).

Mukherjee and Chowdhary (9) reviewed 70 cases of ruptured uterus. Scar rupture accounted for $40 \%$ (28/70) of their cases. In these 28 cases of rupture uterus they reported 4 maternal deaths (14.3\%). To decrease maternal and perinatal morbidity and mortality it is must for obstetricians and gynecologists to diagnose uterine rupture very efficiently so that timely appropriate management can be done for a patient.

\section{Footnotes}

Conflict of Interest: There is no conflict of interest.

Financial Disclosure: There is no financial intrest or support with any drug manufacturer or pharma company.
Funding/Support: There is no funding available.

\section{References}

1. Aziz N, Yousfani S. Analysis of uterine rupture at university teaching hospital Pakistan. Pak J Med Sci. 2015;31(4):920-4. doi: 10.12669/pjms.314.7303. [PubMed: 26430430].

2. Singh A, Shrivastava C. Uterine Rupture: Still a Harsh Reality!. J Obstet Gynaecol India. 2015;65(3):158-61. doi: 10.1007/s13224-014-0551-2. [PubMed: 26085735].

3. Akaba GO, Onafowokan O, Offiong RA, Omonua K, Ekele BA. Uterine rupture: trends and feto-maternal outcome in a Nigerian teaching hospital. Niger J Med. 2013;22(4):304-8. [PubMed: 24283089].

4. Veena P, Habeebullah S, Chaturvedula L. A review of 93 cases of ruptured uterus over a period of 2 years in a tertiary care hospital in South India. J Obstet Gynaecol. 2012;32(3):260-3. doi: 10.3109/01443615.2011.638091. [PubMed: 22369400].

5. Dare FO, Oboro VO. A 15-year analysis of uterine rupture. Int J Gynaecol Obstet. 2002;79(1):27-9. doi: 10.1016/s0020-7292(02)00183-2.

6. Kieser K. A 10-year population-based study of uterine rupture. Obstet Gynecol. 2002;100(4):749-53. doi:10.1016/s0029-7844(02)02161-0.

7. Haakman O, Ambrose D, Katopodis C, Altman AD. Spontaneous rup ture of an unscarred uterus diagnosed postpartum: A case report. J Obstet Gynaecol Can. 2015;37(11):1021-4. doi:10.1016/s1701-2163(16)30052-4.

8. Thisted DL, Mortensen LH, Krebs L. Uterine rupture without previous caesarean delivery: a population-based cohort study. Eur J Obstet Gynecol Reprod Biol. 2015;195:151-5. doi: 10.1016/j.ejogrb.2015.10.013. [PubMed: 26544026].

9. Mukherjee JR, Chowdhary NN. Rupture uterus: A clinical study of 70 cases. J Obstetrics Gynaecol India. 1995;45:85-9. 